\title{
Carbon Coating of Si Thin Flakes and Negative Electrode Properties in Lithium-Ion Batteries
}

\section{Takashi OKUBO, ${ }^{a}$ Tomoyuki YAMADA, $^{a}$ Morihiro SAITO, ${ }^{a}$ Chihiro YODOYA, ${ }^{a}$ Akika KAMEI, ${ }^{a}$ Masato HIROTA, ${ }^{b}$ TOShio TAKENAKA, Akimasa TASAKA, ${ }^{a}$ and Minoru INABA ${ }^{a, *}$}

\author{
a Department of Molecular Chemistry and Biochemistry, Faculty of Science and Engineering, \\ Doshisha University, Kyotanabe, Kyoto 610-0321, Japan \\ b Oike \& Co., Ltd., Kamitoba, Minami-ku, Kyoto 601-8121, Japan \\ * Corresponding author: minaba@mail.doshisha.ac.jp
}

\begin{abstract}
To reduce the high irreversible capacity $\left(Q_{\mathrm{irr}}\right)$ of Si thin flake (Si-LP) negative electrode, carbon-coated Si-LPs were prepared using citric acid as a precursor and their charge/discharge properties were investigated as negative electrodes in lithium-ion batteries. The carbon-coated powder was homogeneously coated with a thin carbon layer (8-10 and 6-8 $\mathrm{nm}$ in thickness for Si-LPs heat-treated at 600 and $700^{\circ} \mathrm{C}$, respectively, $14 \mathrm{wt} \%$ for each). The irreversible capacity $Q_{\text {irr }}$ was successfully reduced to about a half (ca. $1100 \mathrm{mAh} \mathrm{g}^{-1}$ ) of that of the pristine Si-LP $\left(2336 \mathrm{mAh} \mathrm{g}^{-1}\right)$, though the cycleability was slightly deteriorated. The cycleability of Si-LP@Cs was significantly improved by the addition of $10 \mathrm{wt} \% \mathrm{VC}$ in the electrolyte solution. Si-LP@C $\left(700^{\circ} \mathrm{C}\right) \mathrm{kept}$ high discharge capacities over $2000 \mathrm{mAhg}^{-1}$ even after 50 cycles with a reduced $Q_{\text {irr }}$ of ca. $1300 \mathrm{mAh} \mathrm{g}^{-1}$ compared with the pristine Si-LP (ca. $2450 \mathrm{mAh} \mathrm{g}^{-1}$ ).
\end{abstract}

(C) The Electrochemical Society of Japan, All rights reserved.

Keywords : Li-Si Alloy Negative Electrode, Thin Flakes, Carbon-Coating, Irreversible Capacity

\section{Introduction}

In recent years, $\mathrm{Li}-\mathrm{Si}$ alloy negative electrodes have attracted much attention for large-format lithium ion batteries (LIBs) because of their high theoretical capacity (ca. $\left.4200 \mathrm{mAh} \mathrm{g}^{-1}\right) .{ }^{1,2}$ However, poor cycleability and high irreversible capacity $\left(Q_{\text {irr }}\right)$ in the initial charge/discharge cycle are problems to be solved for practical use. The poor capacity retention is ascribed to large volume changes during the charge/discharge cycles, which leads to particle fracture and electrochemical pulverization. ${ }^{3}$ Therefore, relaxation of the physical stress due to the expansion and shrinkage is important to attain good cycleability. This concept has been realized by using Si nanoparticles ${ }^{3-10}$ or nanowires, ${ }^{11-16}$ the former of which are usually as composites with carbon or $\mathrm{SiO}_{x}$ matrices (i.e. $\mathrm{Si} / \mathrm{C}$ or $\left.\mathrm{Si} / \mathrm{SiO}_{x}\right) .{ }^{3-12}$ Another concept is to use thin films of metals, ${ }^{17-21}$ however, the thickness of the film should be less than a few micrometers to obtain good cycleability, which limits the total capacity of the cells. In previous studies, ${ }^{22-26}$ we have reported that the use of Si thin flakes, Si Leaf Powder ${ }^{\circledR}$ (Si-LP, Oike \& Co., Ltd.), is effective for improving the cycleability by relaxation of the stress due to the volume changes. However, the high $Q_{\text {irr }}$ still remained in the first cycle, which is caused by decomposition of the electrolyte solution $^{27}$ as well as irreversible reduction of thin oxide layer on the Si-LP surface during the first charging process as: ${ }^{28}$

$$
\begin{aligned}
& \mathrm{SiO}_{2}+4 \mathrm{Li}^{+}+4 \mathrm{e}^{-} \rightarrow 2 \mathrm{Li}_{2} \mathrm{O}+\mathrm{Si} \\
& 2 \mathrm{SiO}_{2}+4 \mathrm{Li}+4 \mathrm{e}^{-} \rightarrow \mathrm{Li}_{4} \mathrm{SiO}_{4}+\mathrm{Si}
\end{aligned}
$$

It has been reported that the $Q_{\text {irr }}$ due to the electrolyte decomposition can be reduced by making composites with carbon. ${ }^{3-5}$ However, the contents of carbon in these composites are relatively high $(40-80 \%)$ and the practical capacity based on the weight or volume of the composites is significantly reduced. Yoshio et al. reported that a carbon-coated Si powder exhibited not only a good cycleability, but also a low $Q_{\text {irr }}$ owing to a considerable suppression of the electrolyte decomposition regardless of a low content of carbon $(20 \mathrm{wt} \%)^{27}$

In this study, we prepared carbon-coated Si-LPs (Si-LP@Cs) to reduce $Q_{\text {irr }}$ with a minimum content of carbon, and investigated the effects of the carbon-coating on the negative electrode properties of Si-LPs. Furthermore, addition of vinylene carbonate (VC) in the electrolyte solution was also examined to improve the cycleability of Si-LP@Cs.

\section{Experimental}

Si-LP powder (size: $4-5 \mu \mathrm{m}$, thickness: $100 \mathrm{~nm}$ ) was prepared by a physical vapor deposition (PVD) method using vacuum evaporation. The Si-LP powder $(0.1 \mathrm{~g})$ was mixed with citric acid $(0.685 \mathrm{~g})$ as a carbon source in ethanol $(3.4 \mathrm{~mL})$. The mixture was dried and heated either at 600 or $700^{\circ} \mathrm{C}$ for $4 \mathrm{~h}$ in Ar atmosphere. The Si-LP@C samples were characterized by X-ray diffraction (XRD, Rigaku, RINT2000), scanning electron microscopy (SEM, JEOL, JSM7001FD), transmission electron microscopy (TEM, JEOL, JEM2100), Raman spectroscopy (Horiba, T64000) coupled with a Nd/YAG laser (532 nm, Laser Quantum, Ventus 532), thermogravimetry-differential thermal analysis (TG-DTA, Rigaku, Thermo plus TG8120), and X-ray photoelectron spectroscopy (XPS, SHIMADZU, AXIS-165).

For each sample, a slurry was prepared by mixing $83.3 \mathrm{wt} \%$ active material sample, $5.6 \mathrm{wt} \%$ Ketjen Black (KB, Lion Corp., EC600JD) as a conductive agent, and $11.1 \mathrm{wt} \%$ carboxymethyl cellulose sodium salt (NaCMC, Nacalai Tesque) as a binder using water as a solvent. The slurry was coated on copper foil $\left(0.785 \mathrm{~cm}^{2}\right)$ as a current collector, and then dried overnight at $80^{\circ} \mathrm{C}$ under vacuum. A coin-type two-electrode half-cell was constructed of the composite electrode, a separator (Celgard ${ }^{\circledR} 2400$ ), and Li foil (Honjo Metal, $0.5 \mathrm{~mm}$ in thickness) counter electrode in argon-filled glove box (Miwa, MDB-1NKP-DS) with a dew point lower than $-60^{\circ} \mathrm{C}$. 


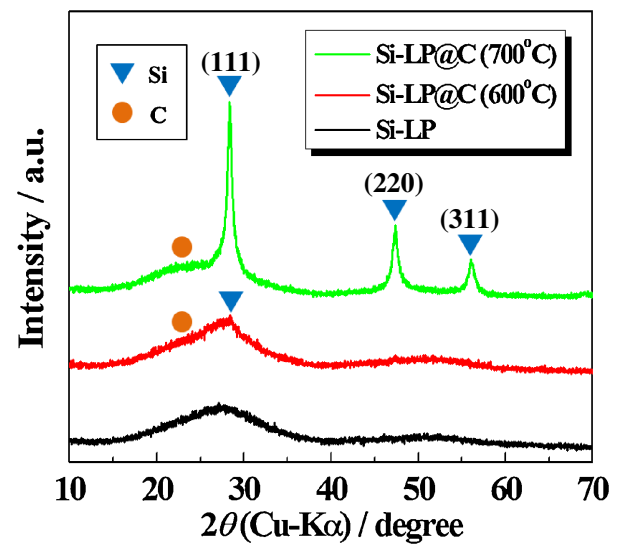

Figure 1. (Color online) XRD patterns of the pristine and carboncoated Si-LPs.
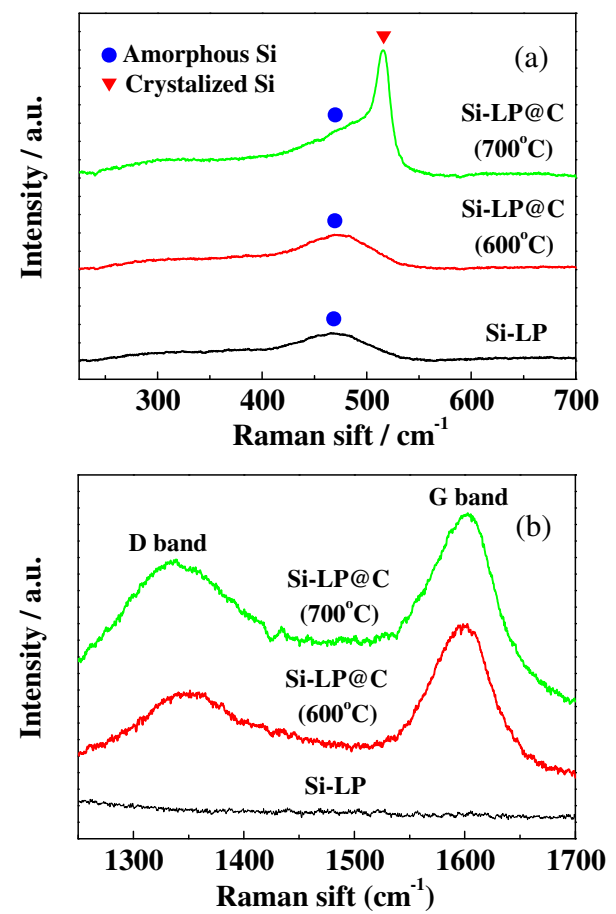

Figure 2. (Color online) Raman spectra of the pristine and carbon-coated Si-LPs. (a) Si and (b) C bands.

The electrolyte solution was $1 \mathrm{M} \mathrm{LiPF}_{6}$ dissolved in a mixture of ethylene carbonate and diethylcarbonate $(\mathrm{EC}+\mathrm{DEC}, 1: 1$ by volume, Kishida Chemicals, Battery Grade). In some experiments, $10 \mathrm{wt} \%$ of VC (Aldrich) was added to the electrolyte solution. The charge/ discharge tests were carried out in the constant current-constant voltage (CC-CV) mode at a C/6 rate between 1.5 and $0.02 \mathrm{~V}$ at $30^{\circ} \mathrm{C}$ with a battery test system (Hokuto Denko, HJ1001SM8).

\section{Results and Discussion}

\subsection{Characterization of Si-LP@Cs}

Figure 1 shows XRD patterns of the pristine and carbon-coated Si-LPs. The pristine sample showed only a broad peak at around $28^{\circ}$ that is assigned to amorphous Si. For Si-LP@C $\left(600^{\circ} \mathrm{C}\right)$, almost no peak assigned to crystalline $\mathrm{Si}$ was observed as well as that of the pristine sample. This indicates that the amorphous phase of $\mathrm{Si}$ for the Si-LP was almost kept after the heat treatment at $600^{\circ} \mathrm{C}$ in the carbon-coating process. On the contrary, the Si-LP@C $\left(700^{\circ} \mathrm{C}\right)$
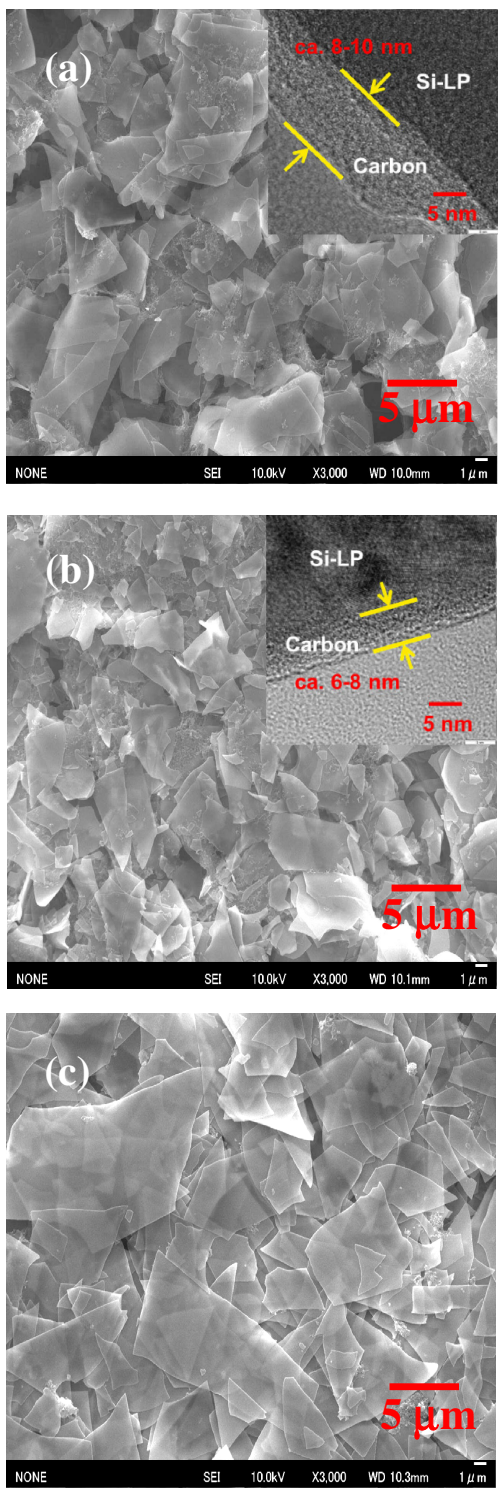

Figure 3. (Color online) SEM and TEM images of electrode surfaces of the Si-LPs. (a) Si-LP@C $\left(600^{\circ} \mathrm{C}\right)$, (b) Si-LP@C $\left(700^{\circ} \mathrm{C}\right)$, and (c) pristine Si-LP. TEM images are inserted in (a) and (b).

exhibited sharp peaks assigned to crystalline $\mathrm{Si}$ at $2 \theta=28,47$, and $56^{\circ}$, indicating the formation of crystallized $\mathrm{Si}$ domains in the amorphous phase of Si-LP particles. In addition, the broad peak centered at $2 \theta=24^{\circ}$, which was assigned to amorphous carbon, was slightly observed for both Si-LP@Cs.

Raman spectra of the carbon-coated and pristine Si-LPs are shown in Fig. 2. In Fig. 2(a), the pristine Si-LP showed a broad band centered at $470 \mathrm{~cm}^{-1}$, which is assigned to amorphous $\mathrm{Si}$. Both Si-LP@Cs exhibited the broad peak at around $470 \mathrm{~cm}^{-1}$, while the sharp peak due to the crystallized $\mathrm{Si}$ appeared at $520 \mathrm{~cm}^{-1}$ only for the Si-LP@C $\left(700^{\circ} \mathrm{C}\right)$. Hence Si-LP@C $\left(600^{\circ} \mathrm{C}\right)$ mostly consisted of the amorphous phase and Si-LP@C $\left(700^{\circ} \mathrm{C}\right)$ contained crystallized domains in the amorphous phase. These results are in good agreement with those obtained from XRD patterns in Fig. 1. In Fig. 2(b), the $\mathrm{D}$ and $\mathrm{G}$ bands derived from carbon were observed at ca. 1350 and $1600 \mathrm{~cm}^{-1}$, respectively, for both Si-LP@Cs. This indicates that poorly graphitized carbon was formed on the surface of the Si-LP@C particles.

Figure 3 shows SEM and TEM images of the pristine and carbon-coated Si-LPs. From SEM observation, Si-LP@Cs had a thin flake structure with an average size of $4-5 \mu \mathrm{m}$. No change was 

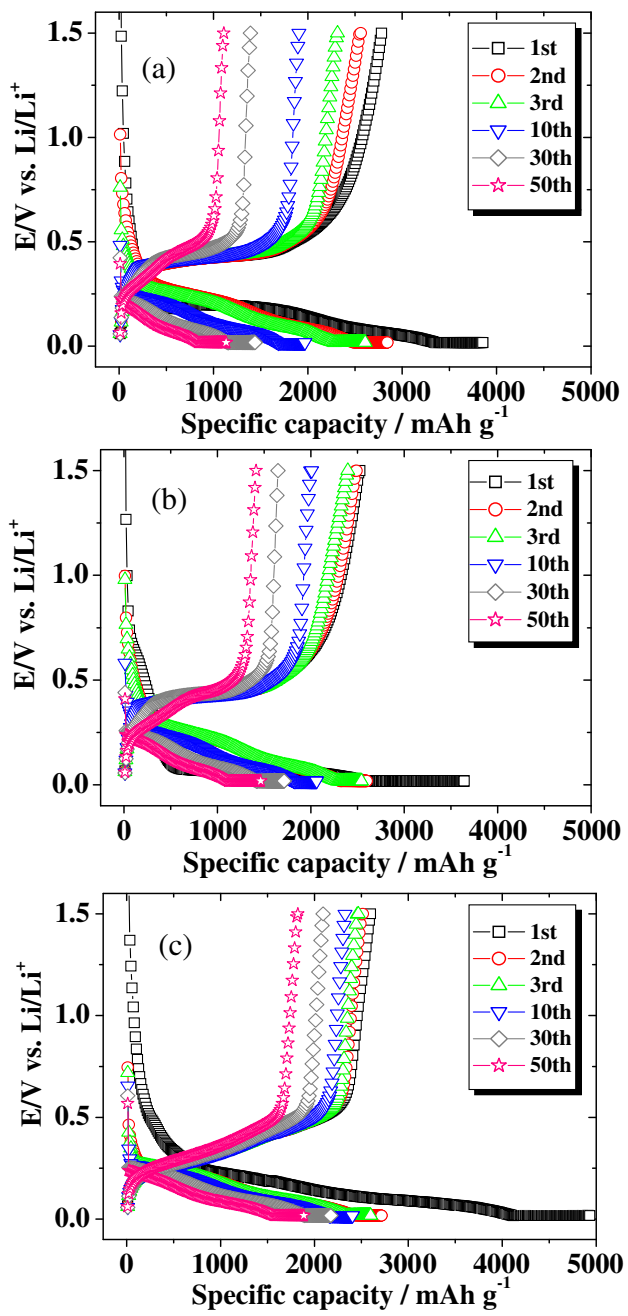

Figure 4. (Color online) Charge/discharge curves of the pristine and carbon-coated Si-LPs at C/6 in $1 \mathrm{M} \mathrm{LiPF}_{6} / \mathrm{EC}+\mathrm{DEC}(1: 1$ by volume). (a) Si-LP@C $\left(600^{\circ} \mathrm{C}\right)$, (b) Si-LP@C $\left(700^{\circ} \mathrm{C}\right)$, and (c) pristine $\mathrm{Si}-\mathrm{LP}$. Potential range: $0.02-1.5 \mathrm{~V}$ vs. $\mathrm{Li} / \mathrm{Li}^{+}$.

confirmed in the shape of Si-LP after the carbon-coating. The TEM images revealed that a carbon layer was homogeneously coated on the surface of Si-LP for both carbon-coated samples. The thickness of the carbon layer was $8-10 \mathrm{~nm}$ for Si-LP@ $\mathrm{C}\left(600^{\circ} \mathrm{C}\right)$ and $6-8 \mathrm{~nm}$ for Si-LP@C $\left(700^{\circ} \mathrm{C}\right)$. The carbon layer slightly became thinner with an increase in heat-treatment temperature, indicating the promotion of graphitization of the carbon layer. From the TG-DTA data (not shown), the content of carbon in Si-LP@C was estimated to be ca. $14 \mathrm{wt} \%$ for both samples.

\subsection{Charge/discharge characteristics of Si-LP@Cs}

Figure 4 compares the charge/discharge curves of the pristine and carbon-coated Si-LPs. The charge, discharge, and irreversible capacities in the first cycle are summarized in Table 1. For the carbon-coated samples, the capacities were corrected for their carbon-contents (14\%), and are shown based on the weight of pure Si in Fig. 4 and Table 1. While the irreversible capacity $Q_{\text {irr }}$ of the pristine sample was very high $\left(2335 \mathrm{mAh} \mathrm{g}^{-1}\right)$, the carbon-coating successfully reduced $Q_{\text {irr }}$ to ca. $1100 \mathrm{mAh} \mathrm{g}^{-1}$. As mentioned earlier, two reasons are considered as the origins of the high $Q_{\text {irr }}$ in the first charging. One is the excess electrolyte decomposition on the surface of Si-LP particles and the other is electrochemical reduction of the $\mathrm{SiO}_{2}$ surface layer of Si-LPs. XPS spectra (not shown) revealed that the pristine $\mathrm{Si}-\mathrm{LP}$ particles were covered with thin $\mathrm{SiO}_{2}$ surface layer. However, the amount of the $\mathrm{SiO}_{2}$ surface layer increased after
Table 1. Charge $\left(Q_{\mathrm{ch}}\right)$, discharge $\left(Q_{\text {dis }}\right)$, and irreversible $\left(Q_{\text {irr }}\right)$ capacities in the first cycle of the pristine and carbon-coated Si-LPs at $\mathrm{C} / 6$ in $\mathrm{LiPF}_{6} / \mathrm{EC}+\mathrm{DEC}(1: 1)$ at $30^{\circ} \mathrm{C}$.

\begin{tabular}{lcccc}
\hline Electrode & VC & $\begin{array}{c}Q_{\text {ch }} \\
\left(\mathrm{mAh} \mathrm{g}^{-1}\right)\end{array}$ & $\begin{array}{c}Q_{\text {dis }} \\
\left(\mathrm{mAh} \mathrm{g}^{-1}\right)\end{array}$ & $\begin{array}{c}Q_{\text {irr }} \\
\left(\mathrm{mAh} \mathrm{g}^{-1}\right)\end{array}$ \\
\hline Si-LP & none & 4931 & 2596 & 2335 \\
Si-LP@C $\left(600^{\circ} \mathrm{C}\right)$ & none & 3853 & 2781 & 1072 \\
Si-LP@C $\left(700^{\circ} \mathrm{C}\right)$ & none & 3642 & 2525 & 1117 \\
\hline Si-LP & $10 \mathrm{wt} \%$ & 5096 & 2651 & 2445 \\
Si-LP@C $\left(600^{\circ} \mathrm{C}\right)$ & $10 \mathrm{wt} \%$ & 4253 & 2696 & 1557 \\
Si-LP@C $\left(700^{\circ} \mathrm{C}\right)$ & $10 \mathrm{wt} \%$ & 4093 & 2776 & 1317 \\
\hline
\end{tabular}

the heat treatment for carbon-coating, probably because the Si-LP particles were further oxidized by a small amount of oxygen impurity in $\mathrm{Ar}$ at high temperatures. The carbon-coating, nevertheless, reduced $Q_{\text {irr }}$ significantly as shown in Fig. 4 and Table 1. It is therefore considered that the carbon-coating effectively suppressed the excess electrolyte decomposition on the surface of $\mathrm{Si}$-LP, which resulted in the reduction of $Q_{\text {irr }}$ in the first cycle. This is probably because the carbon layer is less active for the reductive decomposition of the electrolyte solution than Si surface. ${ }^{27}$ Though it was found that $Q_{\text {irr }}$ can be effectively reduced by the carboncoating, it should be reduced much more for practical applications. As for the reversible (discharge) capacity, the pristine Si-LP, Si$\mathrm{LP} @ \mathrm{C}\left(600^{\circ} \mathrm{C}\right)$, and Si-LP@C $\left(700^{\circ} \mathrm{C}\right)$ had similar initial discharge capacities $\left(2500-2800 \mathrm{mAh} \mathrm{g}^{-1}\right)$.

The carbon-coating process affected the charge/discharge profiles as well. For the pristine Si-LP, the discharge curves started at a low potential (ca. $0.2 \mathrm{~V}$ ) and are sloping, which is typical for amorphous Si samples. However, for both Si-LP@Cs, the discharge curves started at a higher potential with a clear plateau at ca. $0.4 \mathrm{~V}$ in the initial cycles up to 20 or 30 cycles. This profile is characteristic of crystalline Si samples. Dahn et al. reported ${ }^{29}$ that crystalline Si becomes amorphous upon charging, and then a lithiated amorphous $\mathrm{Li}_{x} \mathrm{Si}$ phase was crystallized again to form a $\mathrm{Li}_{15} \mathrm{Si}_{4}$ phase rapidly at ca. $60 \mathrm{mV}$. In the following discharging, the crystalline $\mathrm{Li}_{15} \mathrm{Si}_{4}$ phase coexists with amorphous $\mathrm{Li}_{x} \mathrm{Si}$, which generates the plateau at ca. $0.4 \mathrm{~V}$ on the discharge curve.

It is clear that the change in the charge/discharge profile for SiLP@C was brought about by the heat treatment at high temperatures in the carbon-coating process. However, the results of XRD and Raman analysis in Figs. 1 and 2 showed that Si-LP@C $\left(600^{\circ} \mathrm{C}\right)$ was almost amorphous, while Si-LP@C $\left(700^{\circ} \mathrm{C}\right)$ contained crystalline domains in the amorphous phase. Nevertheless, Si-LP@C $\left(600^{\circ} \mathrm{C}\right)$ showed the charge/discharge profiles similar to those for crystalline $\mathrm{Si}$. These facts mean that the electrochemical properties are more sensitive to the crystallographic structure of $\mathrm{Si}$ than XRD and Raman spectroscopy.

The discharge profiles of Si-LP@Cs changed to sloping at the 50th cycle in Figs. 4(a) and 4(b), which indicated that the crystallized Si domains became gradually amorphous after 20-30 cycles. The amorphization during charging and discharging may be caused by a large stress by a large volume change upon alloying and de-alloying.

The cycleability and the Coulombic efficiency of the pristine and carbon-coated Si-LPs is shown in Figs. 5(a) and 5(b), respectively. From the result of Fig. 5(a), the discharge capacities in the first cycle were similarly high $\left(2500-2800 \mathrm{mAh}^{-1}\right)$ for the pristine and carbon-coated Si-LPs. However a relatively rapid capacity fade was observed for the carbon-coated samples in the initial 10 cycles. This may be due to the crack formation of the carbon-coating by volume 

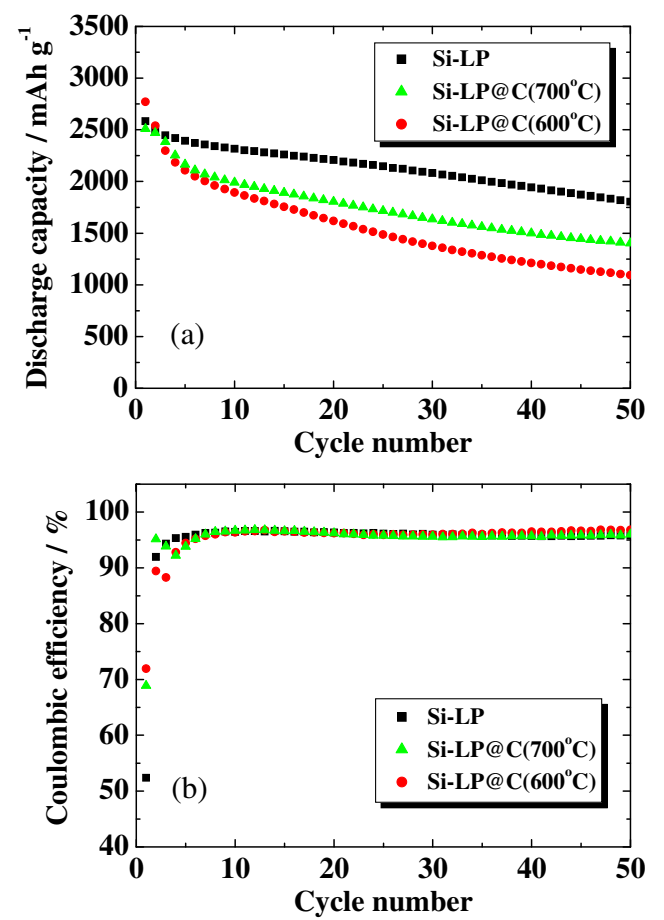

Figure 5. (Color online) Cycleability (a) and Coulombic efficiency (b) of the pristine and carbon-coated Si-LPs at C/6 in $1 \mathrm{M}$ $\mathrm{LiPF}_{6} / \mathrm{EC}+\mathrm{DEC}$ (1:1 by volume). Potential range: $0.02-1.5 \mathrm{~V}$ vs. $\mathrm{Li} / \mathrm{Li}^{+}$.

changes of the Si-LP particles during the initial charge/discharge cycles, by which the electrolyte decomposition occurred on the surface of Si-LP particles. In fact, the Coulombic efficiency of the Si-LP@Cs was slightly lower than that of the pristine sample from the third to the fifth cycle [Fig. 5(b)], though it was higher in the first and second cycle. All Si-LP samples showed high Coulombic efficiencies $(\sim 96 \%)$ from the 6th cycle.

The capacity retention of the carbon-coated samples was slightly poorer than the pristine sample [Fig. 5(a)]; however, it was much better than that of the conventional large-size $\mathrm{Si}$ powder, ${ }^{22-24}$ implying that the thin fake-shape of Si-LP@Cs maintained after the carbon-coating cracked. When the two carbon-coated samples were compared, the capacity retention of Si-LP@C $\left(700^{\circ} \mathrm{C}\right)$ was better than that of Si-LP@C $\left(600^{\circ} \mathrm{C}\right)$. As shown in Figs. 1 and 2, SiLP@C $\left(700^{\circ} \mathrm{C}\right)$ crystallized more than Si-LP@C $\left(600^{\circ} \mathrm{C}\right)$. Therefore the crystallization upon the heat treatment does not deteriorate the cycleability of Si-LP@Cs whose thickness is very thin $(100 \mathrm{~nm})$. The reason for the observed better cycleability of Si-LP@C $\left(700^{\circ} \mathrm{C}\right)$ is not clear at present, but may be related with the nature of the carbon layer formed on Si-LP@ $\mathrm{C}\left(700^{\circ} \mathrm{C}\right)$, which was a little more graphitized than that formed on Si-LP@C $\left(600^{\circ} \mathrm{C}\right)$.

Figure 6 shows SEM images of the electrode surfaces of the pristine and carbon-coated Si-LPs after 50 cycles. Though the carbon-coated Si-LP@C samples were highly agglomerated and large cracks were generated in the electrodes, no pulverization was observed as well as the pristine Si-LP. This is the reason why the SiLP@C electrodes gave relatively good cycleability, and is in good agreement with the results of our previous studies on Si-LPs. ${ }^{22-26}$

\subsection{Effects of VC addition}

It is widely known that the cycleability of Si negative electrode is improved by the addition of VC in the electrolyte solution. ${ }^{9,24-26,30}$ Figure 7 shows cycleability of the pristine and carbon-coated Si-LPs in the presence of $10 \mathrm{wt} \% \mathrm{VC}$ in the electrolyte. The charge, discharge, and irreversible capacities in the first cycle are summa-
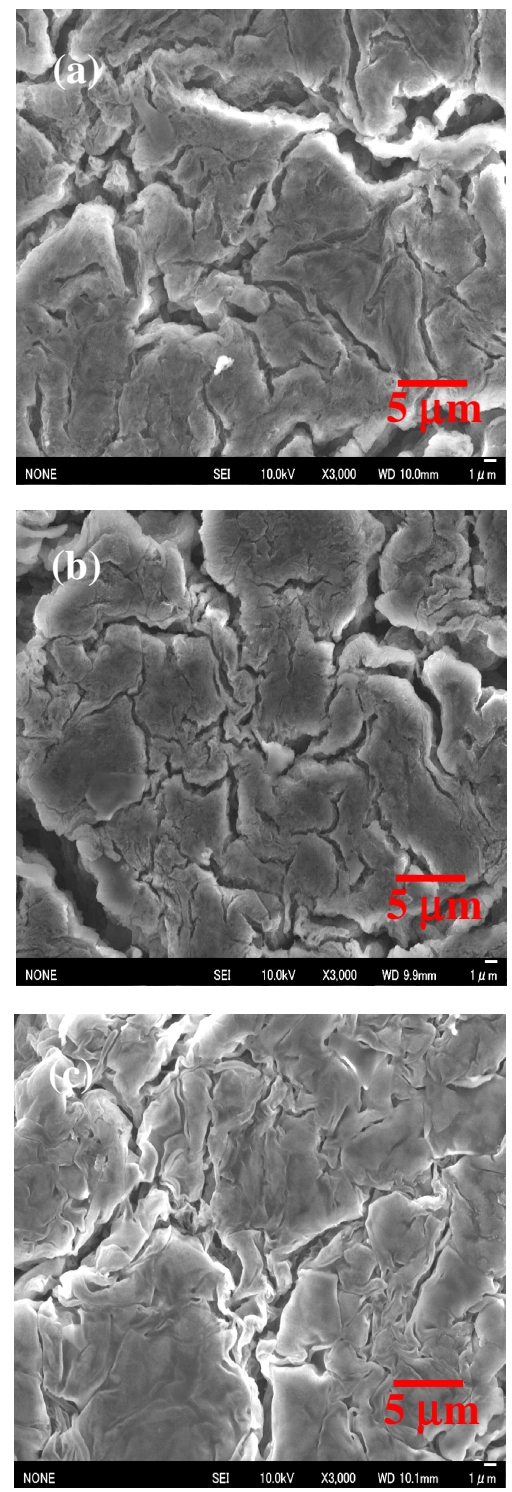

Figure 6. (Color online) SEM images of electrode surfaces of the pristine and carbon-coated Si-LPs after 50 cycles at $\mathrm{C} / 6$ in $1 \mathrm{M}$ $\mathrm{LiPF}_{6} / \mathrm{EC}+\mathrm{DEC}\left(1: 1\right.$ by volume). (a) Si-LP@C $\left(600^{\circ} \mathrm{C}\right)$, (b) Si$\mathrm{LP} @ \mathrm{C}\left(700^{\circ} \mathrm{C}\right)$, and (c) pristine Si-LP.

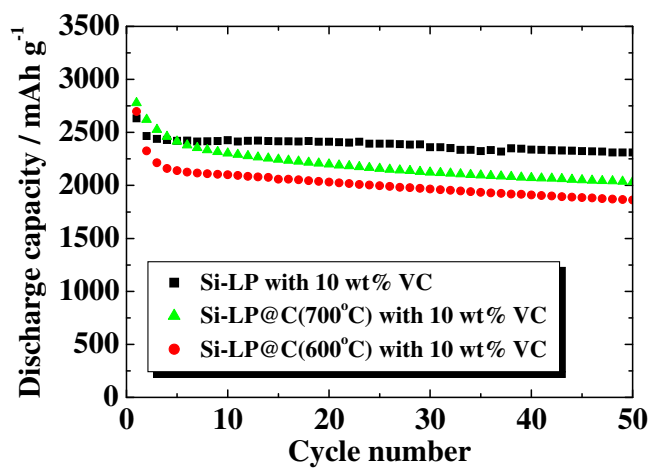

Figure 7. (Color online) Cycleability of the pristine and carboncoated Si-LPs at C/6 in $1 \mathrm{M} \mathrm{LiPF}_{6} / \mathrm{EC}+\mathrm{DEC}(1: 1$ by volume $)+$ $10 \mathrm{wt} \%$ VC. Potential range: $0.02-1.5 \mathrm{~V}$ vs. $\mathrm{Li} / \mathrm{Li}^{+}$.

rized in Table 1. Regardless of carbon-coating, the addition of VC significantly improved the cycleability of each Si-LP sample, though the initial discharge capacity did not remarkably change from that 
without VC shown in Fig. 5. It is widely known that VC is a good SEI-forming additive not only for graphite, but also for Si negative electrodes. ${ }^{9,24-26,30}$ It gives a smooth and homogeneous SEI film on the surface of Si negative electrode and suppresses the SEI growth upon cycling, ${ }^{30}$ resulting in an improvement in cycleability for both the pristine and carbon-coated Si-LP samples shown in Fig. 7.

The carbon-coating resulted in a slightly detrimental effect on the cycleability, and hence the discharge capacity at the 50th cycle was in the order of the pristine $\operatorname{Si}-\mathrm{LP}\left(2324 \mathrm{mAhg}^{-1}\right)>$ Si-LP@C $\left(700^{\circ} \mathrm{C}\right)\left(2033 \mathrm{mAh} \mathrm{g}^{-1}\right)>\mathrm{Si}-\mathrm{LP} @ \mathrm{C}\left(600^{\circ} \mathrm{C}\right)(1862$ $\left.\mathrm{mAh}^{-1}\right)$. This may be due to the crack formation of the carboncoating by volume changes of the Si-LP particles as discussed earlier. As for the irreversible capacity $Q_{\text {irr }}$, the addition of VC increased $Q_{\text {irr }}$ for each sample when compared with that without VC addition. The carbon coating successfully reduced $Q_{\text {irr }}$ to ca. $1300-1550 \mathrm{mAh} \mathrm{g}^{-1}$, while $Q_{\text {irr }}$ of the pristine sample was very high $\left(2445 \mathrm{mAh}^{-1}\right)$. It was again shown that the carbon-coating effectively suppressed the excess electrolyte decomposition on the surface of Si-LPs even in the presence of VC.

\section{Conclusions}

Carbon-coated $\mathrm{Si}$ thin flakes, Si-LP@C $\left(600^{\circ} \mathrm{C}\right)$ and SiLP@ $\left(700^{\circ} \mathrm{C}\right)$, were prepared and their charge/discharge properties were investigated as negative electrodes. The Si-LP@C power was homogeneously coated with a thin carbon layer $(8-10$ and $6-8 \mathrm{~nm}$ in thickness for Si-LP@C $\left(600^{\circ} \mathrm{C}\right)$ and Si-LP@C $\left(700^{\circ} \mathrm{C}\right)$, respectively, $14 \mathrm{wt} \%$ for each). The amorphous Si phase in the pristine Si-LP partly crystallized during the heat treatment in the carbon-coating process, especially for Si-LP@700 $\mathrm{C}$.

The irreversible capacity $Q_{\text {irr }}$ was successfully reduced to a half (ca. $\left.1100 \mathrm{mAh} \mathrm{g}^{-1}\right)$ of that of the pristine Si-LP $\left(2336 \mathrm{mAh} \mathrm{g}^{-1}\right)$, though the cycleability was slightly deteriorated. The reduction of $Q_{\text {irr }}$ clearly indicates that the carbon-coating effectively suppressed the excess electrolyte decomposition on the surface of Si-LP. The crystallization upon the heat treatment did not remarkably deteriorate the cycleability of Si-LP@Cs. The cycleability of SiLP@Cs was significantly improved by addition of $10 \mathrm{wt} \% \mathrm{VC}$ in the electrolyte solution. Si-LP@C $\left(700^{\circ} \mathrm{C}\right)$ kept high discharge capacities over $2000 \mathrm{mAh} \mathrm{g}^{-1}$ even after 50 cycles with a reduced $Q_{\text {irr }}$ of ca. $1300 \mathrm{~mA} \mathrm{~g}^{-1}$ compared with the pristine Si-LP (ca. 2450 $\mathrm{mAh}^{-1}$ ). Unfortunately $Q_{\text {irr }}$ is still high for practical applications and should be reduced much more. Further improvement of the carbon-coating technique is now in progress.

\section{References}

1. R. A. Huggins, J. Power Sources, 81-82, 13 (1999).

2. B. A. Boukamp, G. C. Lesh, and R. A. Huggins, J. Electrochem. Soc., 128, 725 (1981).

3. H. Li, X. Huang, L. Chen, Z. Wu, and Y. Liang, Electrochem. Solid-State Lett., 2, 547 (1999).

4. J. Yang, B. F. Wang, K. Wang, Y. Liu, J. Y. Xie, and Z. S. Wen, Electrochem. Solid-State Lett., 6, A154 (2003).

5. U. Kasavajjula, C. Wang, and A. J. Appleby, J. Power Sources, 163, 1003 (2007).

6. H. Kim, M. Seo, M.-H. Park, and J. Cho, Angew. Chem., Int. Ed., 49, 2146 (2010).

7. J. Yang, Y. Takeda, N. Imanishi, C. Capiglia, J. Y. Xie, and O. Yamamoto, Solid State Ionics, 152-153, 125 (2002).

8. T. Morita and N. Takami, J. Electrochem. Soc., 153, A425 (2006).

9. Y.-S. Hu, R. Demir-Cakan, M.-M. Tittrici, J.-O. Müller, R. Schlögl, M. Antonietti, and J. Maier, Angew. Chem., Int. Ed., 47, 1645 (2008).

10. C.-M. Park, W. Choi, Y. Hwa, J.-H. Kim, G. Jeong, and H.-J. Sohn, J. Mater. Chem., 20, 4854 (2010).

11. H. Kim and J. Cho, Nano Lett., 8, 3688 (2008).

12. L.-F. Cui, Y. Yang, C.-M. Hsu, and Y. Cui, Nano Lett., 9, 3370 (2009).

13. C. K. Chan, H. Peng, G. Liu, K. Mcllwrath, X. F. Zhang, R. A. Huggins, and Y. Cui, Nat. Nanotechnol., 3, 31 (2008).

14. L.-F. Cui, R. Ruffo, C. K. Chan, H. Peng, and Y. Cui, Nano Lett., 9, 491 (2009).

15. C. K. Chan, R. Ruffo, S. S. Hong, R. A. Huggins, and Y. Cui, J. Power Sources, 189, 34 (2009).

16. X. Chen, K. Gerasopoulos, J. Guo, A. Brown, C. Wang, R. Ghodssi, and J. N. Culver, ACS Nano, 4, 5366 (2010).

17. T. Takamura, S. Ohara, M. Uehara, J. Suzuki, and K. Sekine, J. Power Sources, 129, 96 (2004).

18. H. Guo, H. Zhao, C. Yin, and W. Qiu, Mater. Sci. Eng. B, 131, 173 (2006).

19. T. L. Kulova, A. M. Skundin, Yu. V. Pleskov, E. I. Terukov, and O. I. Kon'kov, J. Electroanal. Chem., 600, 217 (2007).

20. J. P. Maranchi, A. F. Hepp, and P. N. Kumta, Electrochem. Solid-State Lett., 6, A198 (2003).

21. J. Yin, M. Wada, K. Yamamoto, Y. Kitano, S. Tanase, and T. Sakai, J. Electrochem. Soc., 153, A472 (2006).

22. M. Saito, K. Nakai, M. Hagiwara, A. Tasaka, T. Takenaka, M. Hirota, A. Kamei, and M. Inaba, ECS Trans., 25(36), 101 (2010).

23. K. Nakai, I. Tsuchioka, M. Saito, A. Tasaka, T. Takenaka, M. Hirota, A. Kamei, and M. Inaba, Electrochemistry, 78, 438 (2010).

24. M. Saito, K. Nakai, T. Yamada, T. Takenaka, M. Hirota, A. Kamei, A. Tasaka, and M. Inaba, J. Power Sources, 196, 6637 (2011).

25. T. Yamada, M. Saito, C. Yodoya, A. Kamei, and M. Hirota, ECS Trans., 41(32), 27 (2012).

26. M. Saito, K. Nakai, T. Yamada, T. Takenaka, M. Hirota, A. Kamei, A. Tasaka, and M. Inaba, Solid State Ionics, in press.

27. M. Yoshio, H. Wang, K. Fukuda, T. Umeno, N. Dimov, and Z. Ogumi, J. Electrochem. Soc., 149(12), A1598 (2002).

28. B. Guo, J. Shu, Z. Wang, H. Yang, L. Shi, Y. Shi, Y. Liu, and L. Chen, Electrochem. Commun., 10, 1876 (2008).

29. J. Li and J. R. Dahn, J. Electrochem. Soc., 154(3), A156 (2007).

30. L. Chen, K. Wang, X. Xie, and J. Xie, J. Power Sources, 174, 538 (2007) 